\title{
Functional Aspects of Emotive-Causative Categorical Semantic Complex
}

\author{
Siutkina Nadezhda Pavlovna ${ }^{1}$ \\ Associate Professor, Perm State National Research University, \\ Perm, Russia. \\ Shustova Svetlana Viktorovna ${ }^{2}$ \\ Professor, Perm State National Research University, \\ Perm, Russia.
}

(date of receiving: August, 2020; date of acceptance: January, 2021)

\begin{abstract}
The authors of the article focus on causative verbs that actualize emotional modification and the emotionally-causative categorical semantic complex that arises during the functioning of these verbs. The categorical semantic complex is considered as the result of intercategory interaction. The purpose of the article is to describe the above complex and its functional features, the object of analysis is a synthetic and analytical emotive causative, and their functional features. The subject of the study is the categorical situation of causation of emotional modification. It is dominant in utterance with emotive causation, but not the only one. For an emotionally causative categorical semantic complex, intercategory interaction with categories of intensity, expressiveness, and talkativeness becomes typical. Verbs of the Russian language, identified from explanatory and synonymous dictionaries, serve as material for the study. The article concludes that the main content of the emotionally-causative categorical semantic complex is the actualization of the positive or negative modification of the emotional state of the object of causation. A categorical semantic complex can include its semantic space and other semantic categories that are subordinate to the corresponding complexes in this category.
\end{abstract}

Keywords: Semantic Category, Emotive Causative, Emotive-Causative Categorical Semantic Complex, Categorical Situation, Causation of Emotional Modification.

1. E-mail: nad975@yandex.ru

2. E-mail: lanaschust@mail.ru; ORCID:0000-0002-8318-7864 


\title{
Функциональные аспекты эмотивно-каузативного категориального семантического комплекса
}

\author{
Сюткина Надежда Павловна ${ }^{1}$ \\ Доцент Пермского государственного \\ национального исследовательского университета, \\ Пермь, Россия \\ Шустова Светлана Викторовна \\ Профессор, \\ Пермский государственный национальный исследовательский университет, \\ Пермь, Россия. \\ (дата получения: август 2020 г.; дата принятия: январь 2021 г.)
}

\begin{abstract}
Аннотация
В фокусе внимания авторов статьи находятся каузативные глаголы, актуализирующие эмоциональную модификацию и эмотивно-каузативный категориальный семантический комплекс, возникающий в процессе функционирования данных глаголов. Категориальный семантический комплекс рассматривается как результат межкатегориального взаимодействия. Целью статьи является описание вышеуказанного комплекса и его функциональных особенностей, объектом анализа являются синтетический и аналитический эмотивные каузативы, и их функциональные особенности. Предметом исследования является категориальная ситуация каузации эмоциональной модификации. Она является доминантной в высказывании с эмотивными каузативами, но не единственной. Для эмотивнокаузативного категориального семантического комплекса типичным становится межкатегориальное взаимодействие с категориями интенсивности, итеративности, аспектуальности и другими. В качестве материала исследования выступают глаголы русского языка, выявленные из толковых и синонимических словарей. В статье сделан вывод о том, что основное содержание эмотивно-каузативного категориального семантического комплекса заключается в актуализации положительной или отрицательной модификации эмоционального состояния у объекта каузации. Категориальный семантический комплекс может включать в свое семантическое пространство другие семантические категории, которые находятся в подчинительном отношении к данному комплексу в изучаемой категориальной ситуации.
\end{abstract}

Ключевые слова: Семантическая Категория, Эмотивный Каузатив, ЭмотивноКаузативный Категориальный Семантический Комплекс, Категориальная Ситуация, Каузация Эмоциональной Модификации.

1. E-mail: nad975@yandex.ru

2. E-mail: lanaschust@mail.ru; ORCID:0000-0002-8318-7864 


\section{Введение}

Наше исследование посвящено категориальному семантическому комплексу, чтобы понять сущность этого явления нам необходимо обратится к таким базовым понятиям, как семантическая категория, категориальная ситуация, среда и межкатегориальное взаимодействие.

В лингвистической литературе встречаются термины «семантическая категория» и «понятийная категория», поэтому встает вопрос об их взаимосвязи. Понятийные категории - это категории ментальной сферы, основывающиеся на логико-психологических категориях и ориентированные на семантические категории языка. Понятийные категории имеют универсальный характер, они представляют собой результат абстрагирования высокой степени, они присущи языку как таковому, в то время как «семантическая категория представляет собой результат интерпретации средствами конкретного языка соответствующей понятийной категории. Интерпретация осуществляется через семантические функции - свойственные данному языку (его системе и норме) потенциальные возможности передачи некоторого содержания теми или иными способами» (Бондарко 1974. 67-68). В результате понятийная категория «получает определенное преломление в системе данного языка, становится элементом его подсистем, подвергается влиянию специфических сторон его строя» (Бондарко 1978. 73), то есть превращается в семантическую категорию.

Не будучи тождественными, семантические и понятийные категории образуют единство, поскольку первые, несмотря на относительную зависимость от системы языка, являются в некотором смысле производными от вторых. Подобная черта объясняется тем, что «семантическое содержание есть понятийное содержание, выраженное средствами данного языка, структурированное языковыми единицами и их соотношениями, включенное в 
систему этого языка и образующее его содержательную сторону», при этом «отражающее различие и взаимодействие аспектов и уровней языка» и «социально объективированное в данном языковом коллективе» (Бондарко 1978. 5).

На уровне взаимодействия семантических и понятийных категорий мы наблюдаем связь языка и мышления, которая делает возможным анализ когнитивных процессов посредством анализа языковых структур.

\section{Основная часть}

Семантические категории в языке представлены в виде особым образом организованных систем. Значения слов в ментальном лексиконе хранятся не изолированно, а находятся в разнообразных отношениях со значениями других слов. Многие слова на основе этих значений можно разделить на определенные организованные единства - семантические поля (Schwarz, Chur 2007. 60). Критерием выделения семантической категории является частичная общность семантических функций взаимодействующих языковых элементов (наличие семантического инварианта при всех различиях вариантов) (Бондарко 1971. 8).

Исследование эмотивно-каузативного категориального семантического комплекса предполагает выявление системы языковых средств, актуализирующих значение каузативности и эмотивности. В фокусе нашего внимания находятся аспекты взаимодействия данных категорий. Такое взаимодействие может быть реализовано как на лексическом, так и на синтаксическом уровне.

Лексический, или синтетический каузатив представляет собой синкретичный глагол, в семном составе которого в неразрывном единстве взаимодействуют обе категории: каузативности и эмотивности: восхищать, восторгать, очаровать, обворожить, разозлить, испугать, печалить, 
удручать и т.п. Так, восхищать - приводить в восхищение, пленять, очаровывать; восторгать - приводить в восторг; радовать - доставлять радость кому-л; очаровать - производить на кого-либо чарующее впечатление, подчинять своему обаянию; обворожить - всецело завладевать чьим-либо вниманием, мыслями, чувствами, очаровывать, пленять, завораживать; разозлить - возбудить злость в ком-либо, привести в состояние злобного раздражения; испугать - вызвать испуг, чувство тревоги, опасения; печалить - повергать кого-либо в печаль, причинять комулибо печаль, огорчать; удручать - сильно огорчать, приводя в подавленное, угнетенное состояние (СТСРЯ). Как мы видим из дефиниций, природа данных лексем синкретична, взаимодействие двух категорий происходит в рамках одной лексемы, а последняя приведенная здесь в качестве синтаксического эмотивного каузатива лексема «удручать» демонстрирует еще более сложный состав. Здесь мы наблюдаем взаимодействие сразу трех категорий: наряду с ведущими для нас категориями эмотивности и каузативности, в этой лексеме актуализируется также категория интенсивности.

- Она восхищала его своей гордой красотой римлянки и свободой говорить и делать решительно все, что ей вздумается (Ngram).

- Хозяйка очаровывала всех своей любезностью; к двенадцати часам был приготовлен в столовой холодный бридж (Ngram).

- Нет, эта женщина определенно меня удручает, - внезапно признался он Клер, и печать горечи тенями глубоких морщин вдруг легла в темноте на его лицьо (Ngram).

- Что же такого Гийом сделал, чтобы разозлить Деграса, известного спокойным нравом и рассудительностью? (Ngram)

Синтаксический, или аналитический каузатив реализуется в функциональных структурах, в которых каждый компонент несет в себе свою 
семантическую нагрузку: глагол актуализирует категорию каузативности, в то время как эмотивная семантика актуализируется именной группой. В качестве примера функциональных структур, актуализирующих эмотивную каузацию можно назвать: причинять горе, приводить в восхищение, поднимать дух, возбуждать злобу, внушать надежду, доводить до исступления, вселять надежду, обольщать надеждой, нагнетать страху, держать в напряжении, сеять панику и т.п.

Каузативный компонент таких структур актуализируется, как правило, глаголом, обладающим прототипическими каузативными свойствами. Такие глаголы выступают как операторы каузативной связи, они составляют ядро категории каузативности. В русском языке к таким глаголам относятся, например: приводить, доставлять, вызывать, доводить, сеять и др. Данные глаголы, имеют следующие значения: приводить: заставлять проникаться чувством, погружаться в переживание, выраженное соответствующим существительным. в какое-либо настроение, расположение духа, в восторг, в замешательство, в уньние, в отчаяние, в ужас, в бешенство. Доставлять: причинять, вызывать удовольствие, радость, огорчение, неприятность, горе, много (немало) хлопот, много (немало) трудностей. Вызывать: возбуждать что-л., быть причиной чего-л., заставлять появиться чувство чего-л. (радости, разочарования), радость, веселье, смех, насмешку, ульбку, восторг, оживление, интерес, желание делать что-л., сочувствие, симпатию, уважение, доверие, удивление, одобрение, воодушевление, недовольство, разочарование, обиду, слезы, сомнение, ненависть, отвращение, возмущение, негодование, протест, раздражение, зависть, злобу, гнев, смущение, беспокойство, волнение, тревогу, недоверие, подозрение, понимание, растерянность, замешательство, панику, возражение, разногласие, спор, полемику, ссору, подъем чего-л., кризис, катастрофу, пожар, сопротивление. Доводить: кого-л., в какое-л. состояние, быть причиной чего-л. до слез, до 
истерики, до отчаяния, до бешенства, до сумасшествия, до безумия. Сеять: распространять среди людей какие-л. идеи, мысли, настроения; приносить с собой, причинять свет, добро, панику, зло, недоверие, вражду, страх, смерть, разрушение (СС). Как мы видим, в сфере каузативности, данные глаголы обладают широким функциональным потенциалом, актуализируя общее каузативное значение, они предполагают именную часть, конкретизирующую область каузации. Нас интересует каузация эмоциональной модификации, то есть, именной компонент актуализирует положительные или отрицательные эмоции, например:

А иногда срывающиеся с моего языка реплики о смысле жизни $и$ параллельности миров приводили ее в ужнас (Ngram).

Если уже живописеи приводит нас в такой восторд, то во сколько же раз сильнее может сделать это поэт? (Ngram).

И себе и людям вокруг себя он доставлял страдания (Ngram).

Я хочу вас поблагодарить от имени всего флота, - сказал он. Вы доставили нам высокую радость (Ngram).

Он - врач! - И что? Он задержан за то, что доставлял беспокойство людям и подстрекал к этому других (Ngram).

Им нравилось внушать страх, они любили вызывать ужсас, $u$ страдание себе подобных им доставляло наслажденье (Ngram).

Речь вызвала восторд. Обращение $к$ народу король готовил самостоятельно, на его составление ушло несколько дней (Ngram).

Его присутствие вызвало восторг (Ngram).

Он понял наконеи, что ждать ему нечего - он не добьется ни счетов, ни денег, ни какой бы то ни было правды, - но продолжал жить в доме и довел Корнелиуса если не до безумия, то чуть ли не до вспьикки храбрости (Ngram). 
Поэтому необходимо, чтобы матери, все без исключения, были просвещенными, образованными женщинами, чтобы и дома, в семье своей, и за ее пределами они сеяли добро (Ngram).

Она мечтала стать великой танцовщицей, я помогала ей бороться с жизненными трудностями и вселять надежду, когда, казалось бы, все уже потеряно (Ngram).

Как показывают примеры, подобные каузативные конструкции демонстрируют признаки грамматикализации. «Главным признаком аналитической формы считается словесное неравенство ее частей: она состоит из разных слов - вспомогательного, выражающего грамматическое значение формы, и знаменательного, являющегося носителем лексического значения, их сумма оказывается равновеликой значению лексического слова» (Дидковская 2012.69). В каузативной ситуации десемантизации подвергается глагол, знаменательным словом выступает существительное или прилагательное. Мы наблюдаем частичную перекатегоризацию каузативного глагола, основной его функцией становится грамматическая функция. Он выступает в качестве маркеров числа, лица, времени, наклонения, залога, утрачивая при этом в той или иной степени свое лексическое значение, и, соответственно, приближаясь в своём функционировании к вспомогательным глаголам, так как образует предикат в сочетании с другими языковыми элементами, которые и отвечают за эмотивную составляющую каузативной ситуации.

Мы рассмотрели эмотивно-каузативный категориальный комплекс «изнутри», в аспекте его содержательной структуры. Очевидно, что мы наблюдаем пример тесного взаимодействия, «взаимопроникновения» семантических категорий каузативности и эмотивности, что и позволяет говорить нам о категориальном семантическом комплексе.

Однако, при функционировании эмотивно-каузативного категориального семантического комплекса, межкатегориальное взаимодействие происходит не 
только на «внутреннем» уровне, но и на «внешнем». Нужно помнить, что основная коммуникативная функция языковых единиц реализуется в высказываниях и целостном тексте. Высказывание - это микросреда функционирования языковых единиц, макросредой является целостный текст. Высказывание и целостный текст представляют собой обладающие признаком целостности упорядоченные множества элементов, связанных в определенную структуру. В высказывании функции и средства низших уровней интегрируются на основе их взаимодействия. Функции грамматических единиц существуют в форме постоянного и регулярного межкатегориального взаимодействия. Соответственно, грамматические единицы, классы и категории должны изучаться вместе с той средой, которая их окружает и с которой они взаимодействуют. В реализации системных значений грамматических категорий роль среды выполняют элементы контекста и речевой ситуации; к среде относятся лексические значения и лексикограмматические разряды слов, влияющие на данную категорию, а также элементы «категориального окружения» - другие грамматические категории, взаимодействующие с категорией, рассматриваемой как исходная система (Бондарко 2004. 87). Применительно к высказыванию (как речевой реализации предложения или сверхфразового единства) среду в ее вербальном выражении составляют взаимодействующие с ним элементы более крупных фрагментов текста и текста в целом. В этих пределах размещаются элементы ближней и дальней среды с постепенными переходами между ними (Бондарко, эл. ресурс). Таким образом, среда - это системно-функциональное понятие, обращение к которому предполагает исследование языковых систем в сфере их взаимодействия с разными типами языковых и речевых окружений.

Функции грамматических единиц существуют в форме постоянного и регулярного межкатегориального взаимодействия. «Существуют множества содержательных структур, которые воспроизводят некоторые линейные 
последовательности, отражающие одну из макро- или микроситуаций в семантическом плане. На обоих уровнях фиксируется взаимодействие этих ситуаций, что приводит к образованию комплексных семантических ситуаций, возникших в результате реализации комбинаторных отношений» (Шустова 2014. 132-133). По отношению к той или иной языковой единице, категории или группировке среда рассматривается как множество языковых элементов, играющее по отношению к исходной системе роль окружения, во взаимодействии с которым она выполняет свою функцию. «Среда по отношению к отдельному высказыванию - это все речевые элементы его окружения в целостном тексте и все элементы дискурса, которые взаимодействуют с исходной речевой (текстовой) системой и влияют на ее свойства» (Бондарко, эл. ресурс). Ситуация каузации эмоциональной модификации является доминантной в общей ситуации высказывания, в котором актуализируется комплекс категориальных характеристик.

Мы рассматриваем класс эмотивных каузативов, категориальное значение которых заключается в актуализации интерперсональной семантики, а именно, каузации изменения эмоционального состояния объекта каузации. Именно это категориальное значение во всей ситуации является доминантным. Роль среды в ситуации с эмотивными каузативами выполняют адвербиальные единицы, модальные слова, дискурсивные маркеры и междометия. Анализ эмпирического материала показал, что в ситуации с эмотивными каузативами наиболее часто взаимодействуют такие функционально-семантические категории, как аспектуальность, таксис, временная локализованность, темпоральность, итеративность (Шустова, Сюткина 2020. 159). Следует помнить о том, что важной составляющей эмотивности является признак интенсивности. В.И. Шаховский говорит о «плотности эмоций», по его определению это «продукт интенсивности и продолжительности эмоций» (Шаховский 2009. 30). Взаимодействие вышеуказанных категорий с 
эмотивными каузативами ведет к актуализации именно признака интенсивности. Рассмотрим это на примере категории итеративности, связанной с категорией аспектуальности:

1. Он всегда всех злил! (Ngram).

2. Он злил меня, даже бесил временами, но при этом меня к нему невероятно тянуло (Ngram).

В приведенных выше примерах интенсификаторы всегда и временами свидетельствуют о количестве повторений каузации эмоций, в первом примере мы наблюдаем высокую степень интенсивности, а во втором - более низкую. Чем чаще повторяются действия, тем о более высокой степени их интенсивности мы можем говорить.

Таким образом, мы наблюдаем актуализацию нескольких категориальных ситуаций, взаимодействие которых приводит к образованию категориального семантического комплекса. Все категории подчинены в такой ситуации исследуемой нами категории эмотивной каузации, тесно взаимодействуя с ней, они образуют категориальный семантический комплекс. В примерах 1 и 2 мы можем говорить об итеративно-интенсивно-эмотивно-каузативном комплексе. Очевидно, что выявление и анализ актуализации таким комплексов представляется перспективным, поскольку демонстрирует реализацию динамических процессов в языке.

\section{Заключение}

В системе функциональной грамматики категории рассматриваются в аспекте исследования функционально-семантических полей и категориальных ситуаций. В речи обычно мы наблюдаем взаимодействие категориальных элементов высказывания, которые представляют собой разные категории. В таком случае мы говорим о категориальном семантическом комплексе, под 
которым понимается совокупность семантических категорий, функционально объединенных общей целью, общим предназначением, общей интенциональностью - актуализацией таких значений, которые возникают на пересечении двух и более категорий. Как правило, в контексте реализуются два или более категориальных значений, имеются в виду значения, сопряженные с функционально-семантическими категориями.

Каузативная ситуация представляет собой взаимодействие двух одушевленных участников, один из которых, каузатор, оказывает воздействие на объект каузации с целью модификации его эмоциональной сферы, поэтому мы выделяем эмотивно-каузативный категориальный комплекс. Основное содержание комплекса заключается в актуализации положительной или отрицательной модификации эмоционального состояния у объекта каузации и реализуется двумя категориальными семами: семой эмотивности и семой каузации. Категориальный семантический комплекс может включать в свое семантическое пространство другие семантические категории, которые находятся в подчинительном отношении к данному комплексу в данной категориальной ситуации, в другой категориальной ситуации эти категории могут стать ведущими.

\section{Литература}

1- Бондарко А. В. (1971). Грамматические категории и контекст. - Л.: «Наука», $114 \mathrm{c}$.

2- Бондарко А. В. (1974). Понятийные категории и языковые семантические функиии в грамматике // Универсалии и типологические исследования. Отв. ред. В.Н. Ярцева. - М.: «Наука», С. 54-79.

3- Бондарко А. В. (1978). Грамматическое значение и смысл. Л.: «Наука», 176 с.

4- Бондарко А. В. (2002). Категории в системе функииональной грамматики // Коммуникативно-смысловые параметры грамматики и текста. Сборник статей, посвященный юбилею Г. А. Золотовой. - М.: Эдиторал УРСС, C. $15-21$.

5- Бондарко А. В. (2004). Теоретические проблемы русской грамматики. - СПб.: Изд-во «Санкт-Петербургский государственный университет», 208 с. 
6- Бондарко А. В. Лингвистика текста в системе функциональной грамматики. URL:

https://portalus.ru/modules/linguistics/rus readme.php? subaction=showfull\&id $=110$ 6122586\&archive $=\&$ start_from $=\& u c a t=\&$ (дата обращения: 19.06.2020)

7- Дидковская В.Г. (2012). Фразеологические сочетания и аналитические конструкиии // Вестник Череповеиякого государственного университета. № 1. T. 2. C. $68-72$.

8- Современный толковый словарь русского языка Т.Ф.Ефремовой. https://dic.academic.ru/dic.nsf/efremova/257979

9- Словарь синонимов русского языка. Электронный ресурс. URL: https://dic.academic.ru/

10- Шаховский В.И. (2009). Эмочии как объект исследования в лингвистике // Вопросы психолингвистики. № 9. С. 29 - 42.

11- Шустова С. В. (2014). Подсистемы системы (на примере функииональносемантических категорий) // Евразийский вестник гуманитарных исследований. Пермь: Пермский институт экономики и финансов. С. 131-137.

12- Шустова С. В., Сюткина Н. П. (2020). Раџиио и эмоџио в грамматике: эмотивно-каузативный категориальный семантический комплекс // Ratio at Emotio: рациональное и эмоциональное в языке и речи. - СПб.: Изд-во русской христианской гуманитарной академии. $170 \mathrm{c}$.

13- Schwarz M. Chur J. (2007). Semantik. Ein Arbeitsbuch. 5., aktualisierte Auflage. Tübingen: Gunter Narr Verlag, 227 S.

\section{Список принятых обозначений и сокращений}

1- СС - Словарь синонимов русского языка.

2- СТСРЯ - Современный толковый словарь русского языка Т. Ф. Ефремовой.

3- Ngram - Google Books Ngram Viewer

\section{Источники иллюстративного материала}

1- Google Books Ngram Viewer - Исследовательский ресурс https://books.google.com/ngrams

\section{Bibliography}

1- Bondarko A. V. (1971). Grammaticheskie kategorii i kontekst. - L.: «Nauka», $114 \mathrm{~s}$. 
2- Bondarko A. V. (1974). Ponjatijnye kategorii i jazykovye semanticheskie funkcii v grammatike // Universalii i tipologicheskie issledovanija. Otv. red. V.N. Jarceva. M.: «Nauka», S. 54-79.

3- Bondarko A. V. (1978). Grammaticheskoe znachenie i smysl. L.: «Nauka», $176 \mathrm{~s}$.

4- Bondarko A. V. (2002). Kategorii v sisteme funkcional'noj grammatiki // Kommunikativno-smyslovye parametry grammatiki $i$ teksta. Sbornik statej, posvjashhennyj jubileju G. A. Zolotovoj. - M.: Jeditoral URSS, S. 15-21.

5- Bondarko A. V. (2004). Teoreticheskie problemy russkoj grammatiki. - SPb.: Izdvo «Sankt-Peterburgskij gosudarstvennyj universitet», $208 \mathrm{~s}$.

6- Bondarko A. V. Lingvistika teksta v sisteme funkcional'noj grammatiki. URL: https://portalus.ru/modules/linguistics/rus_readme.php?subaction=showfull\&id=110 6122586\&archive $=\&$ start_from $=\& u c a t=\&($ data obrashhenija: 19.06.2020)

7- Didkovskaja V. G. (2012). Frazeologicheskie sochetanija $i$ analiticheskie konstrukcii // Vestnik Cherepoveckogo gosudarstvennogo universiteta. № 1. T. 2. S. $68-72$.

8- Sovremennyj tolkovyj slovar russkogo jazyka T.F. Efremovoj. https://dic.academic.ru/dic.nsf/efremova/257979

9- Slovar' sinonimov russkogo jazyka. Jelektronnyj resurs. URL: https://dic.academic.ru/

10- Shahovskij V.I. (2009). Jemocii kak ob\#ekt issledovanija v lingvistike // Voprosy psiholingvistiki. № 9. S. $29-42$.

11- Shustova S. V. (2014). Podsistemy sistemy (na primere funkcional'nosemanticheskih kategorij) // Evrazijskij vestnik gumanitarnyh issledovanij. Perm': Permskij institut jekonomiki i finansov. S. 131-137.

12- Shustova S. V., Sjutkina N. P. (2020). Racio i jemocio v grammatike: jemotivnokauzativnyj kategorial'nyj semanticheskij kompleks // Ratio at Emotio: racional'noe i jemocional'noe $v$ jazyke $i$ rechi. - SPb.: Izd-vo russkoj hristianskoj gumanitarnoj akademii. $170 \mathrm{~s}$.

13- Schwarz M. Chur J. (2007). Semantik. Ein Arbeitsbuch. 5., aktualisierte Auflage. Tübingen: Gunter Narr Verlag, $227 \mathrm{~S}$.

\section{Spisok prinjatyh oboznachenij i sokrashhenij}

1- SS - Slovar' sinonimov russkogo jazyka.

2- STSRJa - Sovremennyj tolkovyj slovar' russkogo jazyka T. F. Efremovoj.

3- Ngram - Google Books Ngram Viewer 


\section{Istochniki illjustrativnogo materiala}

1- Google Books Ngram Viewer - Issledovatel'skij resurs https://books.google.com/ngrams

HOW TO CITE THIS ARTICLE

Сюткина, Н., \& Шустова, С. (2021). Functional Aspects of Emotive-Causative Categorical Semantic Complex. Issledovatel'skiy Zhurnal Russkogo Yazyka I Literatury, 9(1). 127-142.

DOI: $10.52547 /$ iarll.17.127

URL: https://www.journaliarll.ir/index.php/iarll/article/view/138

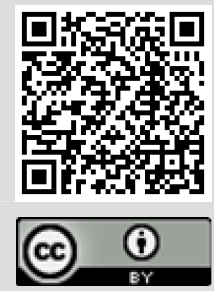


جنبههاى كاربردى مجموعة معنايى مقولهاى عاطفى - سببى

$$
\begin{aligned}
& \text { نادزّدا بِاولونا سيو تكينا' }
\end{aligned}
$$

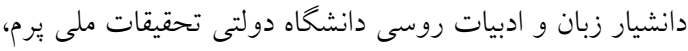

$$
\begin{aligned}
& \text { يرم، روسيه. } \\
& \text { سوتلانا ويكتورونا شوستووات بوتيقات }
\end{aligned}
$$

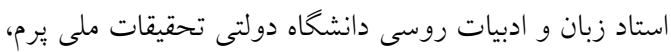

$$
\begin{aligned}
& \text { يرم، روسيه. }
\end{aligned}
$$

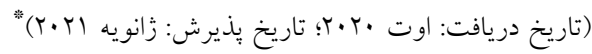

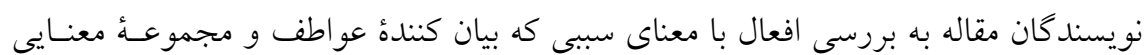

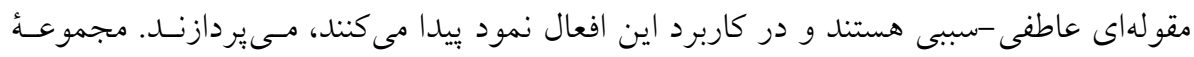

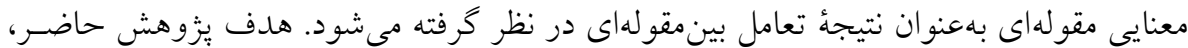

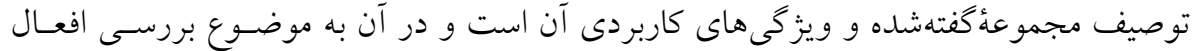

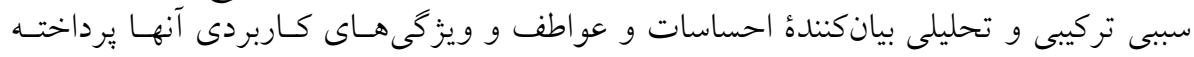

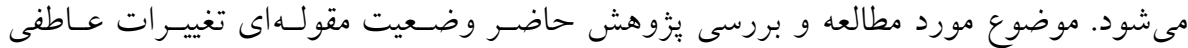

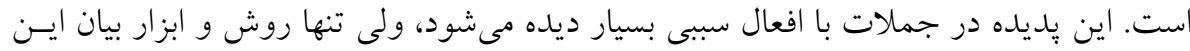

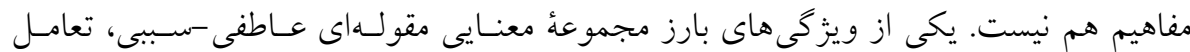

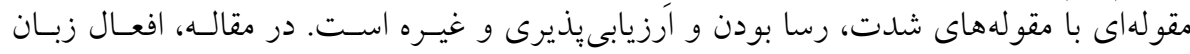

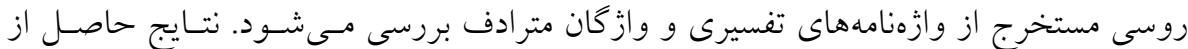

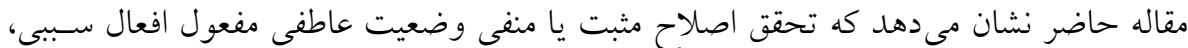

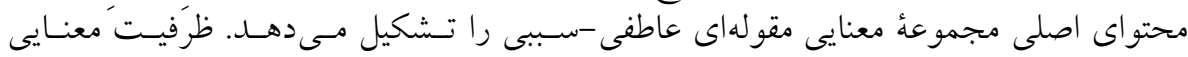

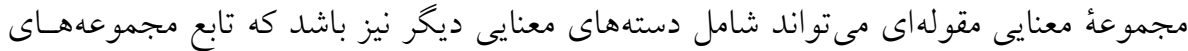
متناظر در اين مقوله هستند.

وازگان كليدى: مقوله معنايى، معلول عاطفى، مجموعه معنايى مقولهاى عاطفى سمببى، وضعيت

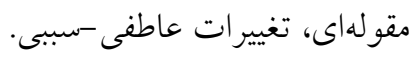

1. E-mail: nad975@yandex.ru

2. E-mail: lanaschust@mail.ru; ORCID:0000-0002-8318-7864 